\title{
PENERAPAN ILMU TAJWID DALAM MEMBACA AL-QUR'AN PADA MATA PELAJARAN BACA TULIS AL-QUR'AN (BTQ)
}

\author{
ANDI ASMAWADI \\ Balai Pengembangan Penjaminan Mutu Pendidikan Vokasi \\ Kelautan Perikanan Teknologi Informasi dan Komunikasi Kemdikbud \\ J1. Diklat No. 30, Pattallassang, Gowa, Sulawesi Selatan, Indonesia \\ andi.asmawadi@kemdikbud.go.id
}

\begin{abstract}
ABSTRAK
Penelitian ini bertujuan untuk mengetahui Penerapan Ilmu Tajwid Dalam Membaca Al-Qur'an Pada Mata Pelajaran Baca Tulis Al-Qur'an (BTQ) tahun pelajaran 2019/2020. Metode penelitian ini adalah Observasi kelas dengan pendekatan kualitatif. Populasi penelitian menggunakan seluruh siswa kelas VIIa SMPN 3 Bontobahari Kabupaten Bulukumba sebanyak 22 orang. Rata-rata hasil pengamatan keterlaksanaan penerapan pembelajaran berlangsung sangat baik. Hasil menunjukkan bahwa pada Surah Al Quraisy, dari 22 siswa, 18 siswa telah benar bacaan tajwidnya, untuk Surat Al Kautsar, 19 orang telah menguasai, dan untuk Surat Al Kaafirun, 20 siswa telah membaca dengan tajwid yang baik. Hal ini menunjukkan bahwa tingkat penerapan metode tajwid dalam pembelajaran BTQ telah dilakukan dengan hasil yang memuaskan.
\end{abstract}

Kata Kunci: Ilmu Tajwid, Baca Tulis Qur'an, Penerapan

\section{PENDAHULUAN}

Sekolah adalah merupakan salah satu wahana yang efektif untuk mentransformasi nilai-nilai budaya dan religi. Tergesernya nilai-nilai religi atau keagamaan diakibatkan derasnya arus teknologi dan informasi dan rentannya daya tahan masyarakat akan arus tersebut sehingga terkesan bahwa nilai religi terlupakan dalam kehidupan, hal inipun terjadi pada proses pembelajaran di sekolah. Masyarakat dan pemerintah dalam hal ini pemerintah yang merupakan fasilitator harus menyadari adanya pergeseran nilai religi yang akan berdampak tidak sempurnanya tujuan pendidikan nasional seperti yang diharapkan .

Kebijakan pemerintah tentang Kurikulum Muatan Lokal yang diintegrasikan dengan Kurikulum 2013 dapat dianggap solusi dari kurangnya porsi jam pelajaran agama di sekolah. Hal ini didukung oleh otonomi daerah sehingga pelaksanaan kurikulum muatan lokal diserahkan pengelolaannya kepada daerah bersangkutan. Mata pelajaran muatan lokal menjembatani antara kebutuhan keluarga dan masyarakat dengan tujuan pendidikan nasional, mata pelajaran ini juga memberikan peluang kepada siswa untuk mengembangkan kemampuannya yang dianggap perlu oleh daerah yang bersangkutan.

Salah satu daerah yang berinisiatif dalam mengembangkan pendidikan agama di sekolah adalah Kabupaten Bulukumba melalui kebijakan pemerintah daerah yang telah ditetapkan sejak tahun 2005 tentang mata pelajajaran Baca Tulis Al-Qur'an sebagai salah satu mata pelajaran muatan lokal yang wajib diajarkan pada semua jenjang 
pendidikan dasar dan menengah di seluruh Kabupaten Bulukumba. Aturan ini dikeluarkan selain untuk menambah jam pelajaran agama di sekolah, juga dimaksudkan untuk mengajarkan pendidikan agama khususnya tentang membaca dan menulis Al-Qur'an sejak dini sehingga selain akan mencetak siswa dan siswi pembaca Al-Qur'an yang handal juga diharapkan mengentaskan buta hurus Al-Qur'an.

Dalam mempelajari Al-Qur'an khususnya dalam hal membacanya terdapat kaidah atau aturan-aturan yang harus dipahami dalam pengucapan huruf-huruf hijaiyah yang biasa disebut dengan ilmu tajwid. Khususnya di SMP Negeri 3 Bontobahari di kelas VII, bahwa sebagian besar siswa sudah mampu membaca Al-Quran, namun dalam membaca ayat-ayatnya ataupun pengucapan huruf-hurufnya masih banyak yang tidak sesuai dengan kaidah atau aturan yang terdapat dalam Ilmu Tajwid karena kesalahan bacaan atau pengucapan huruf dapat mempengaruhi makna atau arti dari suatu ayat atau surah. Hal inilah yang mendasari diterapkannya ilmu tajwid dalam pembelajaran Baca Tulis Al-Qur'an di SMP Negeri 3 Bontobahari khususnya di kelas VII.

Sehubungan uraian di atas, mata pelajaran Baca Tulis Al-Qur'an sebagai salah satu mata pelajaran muatan lokal yang dilaksanakan di SMP Negeri 3 Bontobahari diharapkan akan mencetak anak didik yang fasih dan lancar dalam membaca Al-Qur'an sesuai dengan kaidah ilmu tajwid. Berkaitan dengan hal itu penulis terinspirasi untuk meneliti dengan judul Penerapan Ilmu Tajwid Dalam Membaca Al-Qur'an Pada Mata Pelajaran Baca Tulis Al-Qur'an (BTQ) di Kelas VII SMP Negeri 3 Bontobahari Kabupaten Bulukumba.

\section{METODE PENELITIAN}

Pendekatan yang digunakan dalam penelitian ini adalah pendekatan kualitatif, yaitu prosedur penelitian yang menghasilkan data deskriptif atau bersifat penggambaran secara kualitatif tentang penerapan ilmu tajwid dalam membaca AlQur'an. Penggunaan pendekatan kualitatif didasarkan atas pertimbangan bahwa pendekatan ini menyajikan secara langsung hubungan antara peneliti dengan informan maupun dalam kegiatan observasi yang dilakukan secara langsung oleh peneliti dalam mengungkap dan mengkaji secara mendalam fokus penelitian.

Sebagai penelitian deskriptif kualitatif, maka peneliti ini akan mengkaji tentang penerapan ilmu tajwid dalam membaca AL-Qur' an pada mata pelajaran Baca Tulis AlQur'an (BTQ) di kelas VII SMP Negeri 3 Bontobahari Kabupaten Bulukumba. Unit analisis penelitian ini adalah guru mata pelajaran Baca Tulis Al-Qur'an di kelas VII SMP Negeri 3 Bontobahari sebanyak 1 orang dan kelas yang belajar mata pelajaran Baca Tulis Al-Qur'an dengan menetapkan 1 kelas yaitu kelas VIIa SMP Negeri 3 Bontobahari sebagai obyek penelitian.

\section{HASIL DAN PEMBAHASAN}

Penerapan ilmu tajwid dalam membaca Al-Qur'an pada mata pelajaran baca tulis Al-Qur' an (BTQ) di kelas VII SMP Negeri 3 Bontobahari Kabupaten Bulukumba dilakukan dalam rangka meningkatkan kemampuan siswa dalam membaca kitab suci Al-Qur'an yang sesuai dengan kaidah dan hukum bacaan yang terdapat dala ilmu tajwid. Selain itu, penerapan ilmu tajwid bertujuan untuk menghindari kesalahan 
bacaan pada saat membaca Al-Qur'an karena dapat mempengaruhi makna atau terjemahan pada ayat atau surah yang dibaca.

Proses pembelajaran ilmu tajwid menuntut keaktifan guru dan peserta didik. Oleh karena itu, guru harus profesional dan dituntut menguasai ilmu tajwid dengan baik sehingga memudahkan pemberian materi pelajaran kepada peserta didik.

Penerapan ilmu tajwid dalam membaca Al-Qur'an pada mata pelajaran baca tulis Al-Qur'an (BTQ) di kelas VIIa SMP Negeri 3 Bontobahari Kabupaten Bulukumba pada hakikatnya dilaksanakan sesuai tuntutan kurikulum berdasarkan tahapan pembelajaran, meliputi: tahap persiapan (pra-instruksional), tahap pelaksanaan pembelajaran dan tahap evaluasi dan tindak lanjut. Setiap tahapan tersebut saling berkaitan satu sama lainnya dengan mempengaruhi optimalisasi pembelajaran dalam rangka pencapaian tujuan pembelajaran.

Pemberian materi pelajaran oleh guru dengan metode praktek yakni dengan cara guru mempraktekkan terlebih dahulu surah bacaan yang akan diajarkan kemudian mempraktekkan cara melafalkan huruf-huruf hijaiyah dalam surah serta menjelaskan hukum-hukum tajwid dalam surah tersebut. Proses pembelajaran pada kemampuan siswa dalam membaca surah, kemampuan melafalkan huruf-huruf hijaiyah dalam surah tersebut serta kemampuan mengidentifikasi hukum-hukum ilmu tajwid dalam surah yang diajarkan.

Berdasarkan hasil observasi di kelas VIIa yang berjumlah 22 siswa telah menerapkan ilmu tajwid dengan baik dilihat dari aspek kemampuan siswa dalam membaca surah, kemampuan melafalkan huruf-huruf hijaiyah dalam surah tersebut serta kemampuan mengidentifikasi hukum-hukum ilmu tajwid dalam surah yang diajarkan.

Tabel 1. Hasil Penilaian Bacaan dan Tajwid Surah Al-Quraisy.

\begin{tabular}{|c|c|c|c|c|c|c|c|}
\hline \multirow{3}{*}{ No. } & \multirow{3}{*}{$\begin{array}{l}\text { Nama } \\
\text { Siswa/Inisial }\end{array}$} & \multicolumn{6}{|c|}{ Hasil Penilaian } \\
\hline & & \multicolumn{2}{|c|}{ Bacaan } & \multicolumn{2}{|c|}{ Hukum Tajwid } & \multicolumn{2}{|c|}{$\begin{array}{l}\text { Pengucapan } \\
\text { Huruf Hijaiyah }\end{array}$} \\
\hline & & Benar & $\begin{array}{l}\text { Tidak } \\
\text { Benar }\end{array}$ & Benar & $\begin{array}{l}\text { Tidak } \\
\text { Benar }\end{array}$ & Benar & $\begin{array}{l}\text { Tidak } \\
\text { Benar }\end{array}$ \\
\hline 1 & AA & $\mathrm{V}$ & - & $\mathrm{V}$ & - & - & $\mathrm{V}$ \\
\hline 2 & $\mathrm{AE}$ & - & V & V & - & V & - \\
\hline 3 & A & V & - & - & $\mathrm{V}$ & $\mathrm{V}$ & - \\
\hline 4 & BA & V & - & V & - & V & - \\
\hline 5 & DK & $\mathrm{V}$ & - & $\mathrm{V}$ & - & V & - \\
\hline 6 & $\mathrm{H}$ & - & V & $\mathrm{V}$ & - & V & - \\
\hline 7 & $\mathrm{AL}$ & $\mathrm{V}$ & - & V & - & V & - \\
\hline 8 & AR & $\mathrm{V}$ & - & $\mathrm{V}$ & - & - & $\mathrm{V}$ \\
\hline 9 & $\mathrm{M}$ & $\mathrm{V}$ & - & - & $\mathrm{V}$ & $\mathrm{V}$ & - \\
\hline 10 & SR & - & V & V & - & V & - \\
\hline 11 & MI & V & - & V & - & V & - \\
\hline 12 & RS & V & - & V & - & V & - \\
\hline 13 & SK & - & V & V & - & V & - \\
\hline
\end{tabular}




\begin{tabular}{|l|l|l|l|l|l|l|l|}
\hline 14 & K & V & - & V & - & V & - \\
\hline 15 & AA & - & V & V & - & - & V \\
\hline 16 & F & - & V & V & - & V & - \\
\hline 17 & N & V & - & - & V & V & - \\
\hline 18 & NH & V & - & V & - & V & - \\
\hline 19 & H & V & - & - & V & V & - \\
\hline 20 & AA & V & - & V & - & V & - \\
\hline 21 & NI & V & - & V & - & V & - \\
\hline 22 & KD & V & - & V & - & - & V \\
\hline \multicolumn{2}{|l}{ JUMLAH } & 16 & 6 & 18 & 4 & 18 & 4 \\
\hline
\end{tabular}

Tabel 2. Hasil Penilaian Bacaan dan Tajwid Surah Al-Kautsar

\begin{tabular}{|c|c|c|c|c|c|c|c|}
\hline \multirow{3}{*}{ No. } & \multirow{3}{*}{$\begin{array}{l}\text { Nama } \\
\text { Siswa/Inisial }\end{array}$} & \multicolumn{6}{|c|}{ Hasil Penilaian } \\
\hline & & \multicolumn{2}{|c|}{ Bacaan } & \multicolumn{2}{|c|}{ Hukum Tajwid } & \multicolumn{2}{|c|}{$\begin{array}{l}\text { Pengucapan } \\
\text { Huruf Hijaiyah }\end{array}$} \\
\hline & & Benar & $\begin{array}{l}\text { Tidak } \\
\text { Benar }\end{array}$ & Benar & $\begin{array}{l}\text { Tidak } \\
\text { Benar }\end{array}$ & Benar & $\begin{array}{l}\text { Tidak } \\
\text { Benar }\end{array}$ \\
\hline 1 & $\mathrm{AA}$ & $\mathrm{V}$ & - & $\mathrm{V}$ & - & $\mathrm{V}$ & - \\
\hline 2 & $\mathrm{AE}$ & $\mathrm{V}$ & - & $\mathrm{V}$ & - & - & $\mathrm{V}$ \\
\hline 3 & A & - & $\mathrm{V}$ & - & $\mathrm{V}$ & $\mathrm{V}$ & - \\
\hline 4 & BA & $\mathrm{V}$ & - & $\mathrm{V}$ & - & $\mathrm{V}$ & - \\
\hline 5 & DK & $\mathrm{V}$ & - & $\mathrm{V}$ & - & $\mathrm{V}$ & - \\
\hline 6 & $\mathrm{H}$ & $\mathrm{V}$ & - & $\mathrm{V}$ & - & - & $\mathrm{V}$ \\
\hline 7 & $\mathrm{AL}$ & $\mathrm{V}$ & - & - & $\mathrm{V}$ & - & $\mathrm{V}$ \\
\hline 8 & AR & $\mathrm{V}$ & - & - & $\mathrm{V}$ & $\mathrm{V}$ & - \\
\hline 9 & $\mathrm{M}$ & - & $\mathrm{V}$ & - & $\mathrm{V}$ & $\mathrm{V}$ & - \\
\hline 10 & SR & $\mathrm{V}$ & - & $\mathrm{V}$ & - & $\mathrm{V}$ & - \\
\hline 11 & MI & - & $\mathrm{V}$ & $\mathrm{V}$ & - & $\mathrm{V}$ & - \\
\hline 12 & $\mathrm{RS}$ & $\mathrm{V}$ & - & $\mathrm{V}$ & - & $\mathrm{V}$ & - \\
\hline 13 & SK & $\mathrm{V}$ & - & $\mathrm{V}$ & - & $\mathrm{V}$ & - \\
\hline 14 & $\mathrm{~K}$ & $\mathrm{~V}$ & - & $\mathrm{V}$ & - & $\mathrm{V}$ & - \\
\hline 15 & AA & $\mathrm{V}$ & - & $\mathrm{V}$ & - & $\mathrm{V}$ & - \\
\hline 16 & $\mathrm{~F}$ & $\mathrm{~V}$ & - & $\mathrm{V}$ & - & $\mathrm{V}$ & - \\
\hline 17 & $\mathrm{~N}$ & $\mathrm{~V}$ & - & - & $\mathrm{V}$ & $\mathrm{V}$ & - \\
\hline 18 & $\mathrm{NH}$ & $\mathrm{V}$ & - & - & $\mathrm{V}$ & $\mathrm{V}$ & - \\
\hline 19 & $\mathrm{H}$ & $\mathrm{V}$ & - & $\mathrm{V}$ & - & $\mathrm{V}$ & - \\
\hline 20 & $\mathrm{AA}$ & $\mathrm{V}$ & - & $\mathrm{V}$ & - & $\mathrm{V}$ & - \\
\hline 21 & NI & $\mathrm{V}$ & - & $\mathrm{V}$ & - & $\mathrm{V}$ & - \\
\hline 22 & KD & $\mathrm{V}$ & - & $\mathrm{V}$ & - & $\mathrm{V}$ & - \\
\hline \multicolumn{2}{|c|}{ JUMLAH } & 19 & 3 & 17 & 5 & 19 & 3 \\
\hline
\end{tabular}


Tabel 3. Hasil Penilaian Bacaan dan Tajwid Surah Al-Kaafirun

\begin{tabular}{|c|c|c|c|c|c|c|c|}
\hline \multirow{3}{*}{ No. } & \multirow{3}{*}{$\begin{array}{l}\text { Nama } \\
\text { Siswa/Inisial }\end{array}$} & \multicolumn{6}{|c|}{ Hasil Penilaian } \\
\hline & & \multicolumn{2}{|c|}{ Bacaan } & \multicolumn{2}{|c|}{ Hukum Tajwid } & \multicolumn{2}{|c|}{$\begin{array}{l}\text { Pengucapan } \\
\text { Huruf Hijaiyah }\end{array}$} \\
\hline & & Benar & $\begin{array}{l}\text { Tidak } \\
\text { Benar }\end{array}$ & Benar & $\begin{array}{l}\text { Tidak } \\
\text { Benar }\end{array}$ & Benar & $\begin{array}{l}\text { Tidak } \\
\text { Benar }\end{array}$ \\
\hline 1 & AA & $\mathrm{V}$ & - & $\mathrm{V}$ & - & $\mathrm{V}$ & - \\
\hline 2 & $\mathrm{AE}$ & $\mathrm{V}$ & - & $\mathrm{V}$ & - & $\mathrm{V}$ & - \\
\hline 3 & $\mathrm{~A}$ & $\mathrm{~V}$ & - & $\mathrm{V}$ & - & $\mathrm{V}$ & - \\
\hline 4 & BA & $\mathrm{V}$ & - & $\mathrm{V}$ & - & $\mathrm{V}$ & - \\
\hline 5 & DK & $\mathrm{V}$ & - & $\mathrm{V}$ & - & $\mathrm{V}$ & - \\
\hline 6 & $\mathrm{H}$ & - & - & $\mathrm{V}$ & - & $\mathrm{V}$ & - \\
\hline 7 & $\mathrm{AL}$ & $\mathrm{V}$ & - & $\mathrm{V}$ & - & - & $\mathrm{V}$ \\
\hline 8 & AR & $\mathrm{V}$ & - & $\mathrm{V}$ & - & $\mathrm{V}$ & - \\
\hline 9 & M & $\mathrm{V}$ & - & $\mathrm{V}$ & - & $\mathrm{V}$ & - \\
\hline 10 & SR & $\mathrm{V}$ & - & $\mathrm{V}$ & - & $\mathrm{V}$ & - \\
\hline 11 & MI & $\mathrm{V}$ & - & - & $\mathrm{V}$ & $\mathrm{V}$ & - \\
\hline 12 & $\mathrm{RS}$ & $\mathrm{V}$ & - & $\mathrm{V}$ & - & $\mathrm{V}$ & - \\
\hline 13 & SK & $\mathrm{V}$ & - & $\mathrm{V}$ & - & $\mathrm{V}$ & - \\
\hline 14 & $\mathrm{~K}$ & - & $\mathrm{V}$ & $\mathrm{V}$ & - & $\mathrm{V}$ & - \\
\hline 15 & $\mathrm{AA}$ & $\mathrm{V}$ & - & $\mathrm{V}$ & - & $\mathrm{V}$ & - \\
\hline 16 & $\mathrm{~F}$ & $\mathrm{~V}$ & - & $\mathrm{V}$ & - & $\mathrm{V}$ & - \\
\hline 17 & $\mathrm{~N}$ & $\mathrm{~V}$ & - & $\mathrm{V}$ & - & $\mathrm{V}$ & - \\
\hline 18 & $\mathrm{NH}$ & $\mathrm{V}$ & - & $\mathrm{V}$ & - & - & $\mathrm{V}$ \\
\hline 19 & $\mathrm{H}$ & $\mathrm{V}$ & - & $\mathrm{V}$ & - & $\mathrm{V}$ & - \\
\hline 20 & $\mathrm{AA}$ & $\mathrm{V}$ & - & $\mathrm{V}$ & - & - & $\mathrm{V}$ \\
\hline 21 & $\mathrm{NI}$ & $\mathrm{V}$ & - & $\mathrm{V}$ & - & $\mathrm{V}$ & - \\
\hline 22 & $\mathrm{KD}$ & $\mathrm{V}$ & - & $\mathrm{V}$ & - & $\mathrm{V}$ & - \\
\hline \multicolumn{2}{|c|}{ JUMLAH } & 20 & 2 & 21 & 1 & 19 & 3 \\
\hline
\end{tabular}

Keterangan: $\mathrm{B}=$ Benar, $\mathrm{TB}=$ Tidak Benar

Dari hasil penilaian terhadap bacaan surah Al-Quraisy dari 22 orang siswa sebagian besar yakni 16 orang yang membaca surah Al-Quraisy dengan cara benar dan hanya 4 orang siswa yang tidak benar bacaannya. Demikian pula terhadap pelafalan huruf hijaiyah dalam surah Al-Quraisy dari 22 orang siswa sebagian besar yakni 18 orang yang melafalkan huruf hijaiyah dalam surah Al-Quraisy dengan cara benar dan hanya 4 orang siswa yang tidak benar pelafalan hurufnya. Sedangkan dari hasil penilaian terhadap hukum tajwid dalam surah Al-Quraisy dari 22 orang siswa sebagian besar yakni 18 orang yang mengidentifikasi hukum tajwid dalam surah Al-Quraisy dengan cara benar dan hanya 4 orang siswa tidak benar tajwidnya. 
Demikian halnya dari hasil penilaian terhadap bacaan surah Al-Kautsar dari 22 orang siswa sebagian besar yakni 19 orang yang membaca surah Al-Kautsar dengan cara benar dan hanya 3 orang siswa yang tidak benar bacaannya. Dan dari hasil penilaian terhadap pelafalan huruf hijaiyah dalam surah Al-Kautsar dari 22 orang sebagian besar yakni 17 orang yang melafalkan huruf hijaiyah dalam surah Al-Kautsar dengan cara benar dan hanya 5 orang siswa yang tidak benar pelafalan hurufnya. Sedangkan hasil penilaian terhadap hukum tajwid dalam surah Al-Kautsar dari 22 orang siswa sebagian besar yakni 19 orang yang mengidentifikasi hukum tajwid dalam surah Al-Kautsar dengan cara benar dan hanya 3 orang siswa yang tidak benar tajwidnya.

Sedangkan dari hasil penilaian terhadap bacaan surah Al-Kaafirun dari 22 orang siswa sebagian besar yakni 20 orang yang membaca surah Al-Kaafirun dengan cara benar dan hanya 2 orang siswa yang tidak benar bacaannya. Dan hasil penilaian terhadap pelafalan huruf hijaiyah dalam surah Al-Kaafirun dari 22 orang siswa sebagian besar yakni 21 orang yang melafalkan huruf hijaiyah dalam surah Al-Kaafirun dengan cara benar dan hanya 1 orang siswa yang tidak benar pelafalan hurufnya. Sedangkan hasil penilaian terhadap hukum tajwid dalam surah Al-Kaafirun dari 22 orang siswa kelas sebagian besar yakni 19 orang yang mengidentifikasi hukum tajwid dalam surah Al-Kaafirun dengan cara benar dan hanya 3 orang siswa yang kategori tidak benar.

Dengan mencermati uraian diatas maka, dapat di simpulkan bahwa secara keseluruhan penerapan ilmu tajwid dalam membaca Al-Qur'an pada mata pelajaran baca tulis Al-Qur'an (BTQ) di kelas VIIa SMP Negeri 3 Bontobahari Kabupaten Bulukumba telah diterapkan secara maksimal sesuai yang diharapkan dilihat dari kriteria dan skor penilaian yang dicapai siswa. Hal ini disebabkan karena optimalisasi siswa dalam mengikuti proses pembelajaran walaupun sebagian kecil dari siswa masih perlu bimbingan sehingga kedepannya diharapkan penerapan ilmu tajwid dapat berlangsung lebih optimal dan lebih ditingkatkan lagi sehingga pencapaian kriteria dan skor penilaian dapat mencapai hasil yang lebih maksimal.

Hal lain yang menyebabkan diterapkannya ilmu tajwid dalam membaca AlQur'an secara maksimal dapat dilihat dari kurikulum dengan pencapain tujuan pembelajaran di kelas VIIa SMP Negeri 3 Bontobahari Kabupaten Bulukumba, dari hasil dokumentasi yang dilakukan oleh peneliti dengan melihat kurikulum mata pelajaran Baca Tulis al-Qur'an dan membandingkan dengan hasil observasi pada pembelajaran terdapat kesesuaian antara kurikulum dengan pencapaian tujuan pembelajaran.

Penerapan ilmu tajwid dalam membaca Al-Qur'an pada mata pelajaran baca tulis Al-Qur' an (BTQ) di kelas VII SMP Negeri 3 Bontobahari Kabupaten Bulukumba juga masih terdapat berbagai kendala. Kendala-kendala tersebut adalah: adanya siswa yang kurang tanggap atau lambat dalam memahami materi pelajaran, siswa masih kurang latihan dalam membaca Al-Qur' an dan keterbatasan media yakni kitab suci Al-Qur'an yang tidak menjangkau seluruh siswa.

Sehubungan dengan kendala tersebut, maka upaya yang ditempuh guru dalam mengatasi kendala tersebut berupa: Berupaya agar siswa yang lambat dalam belajar duduk berdekatan dengan siswa yang cepat tanggap agar dapat saling membantu dalam 
belajar, memberikan pengarahan agar siswa memperbanyak latihan membaca AlQur'an dengan tajwid utamanya di rumah dan berupaya agar siswa masing-masing membawa media Al-Qur'an sehingga keterbatasan jumlah media dapat diatasi.

\section{KESIMPULAN}

Penerapan ilmu tajwid dalam membaca Al-Qur'an di kelas VII meliputi 3 (tiga) tahap, yaitu: (a) tahap persiapan, tahap pelaksanaan, serta tahap evaluasi dan tindak lanjut. Pemberian materi pelajaran oleh guru dengan metode praktek yakni dengan cara guru mempraktekkan terlebih dahulu surah bacaan yang akan diajarkan kemudian mempraktekkan cara melafalkan huruf-huruf hijaiyah dalam surah serta menjelaskan hukum-hukum tajwid dalam surah tersebut. Penerapan ilmu tajwid dalam membaca AlQur'an pada mata pelajaran baca tulis Al-Qur'an (BTQ) di kelas VIIa SMP Negeri 3 Bontobahari Kabupaten Bulukumba telah diterapkan secara maksimal sesuai yang diharapkan dilihat dari kriteria dan skor penilaian yang dicapai siswa. Kendala-kendala yang dihadapi adalah: adanya siswa yang kurang tanggap atau lambat dalam memahami materi pelajaran, siswa masih kurang latihan dalam membaca Al-Qur'an dan keterbatasan media yakni kitab suci Al-Qur'an yang tidak menjangkau seluruh siswa. Sehubungan dengan kendala tersebut, maka upaya yang ditempuh guru dalam mengatasi kendala tersebut berupa: Berupaya agar siswa yang lambat dalam belajar duduk berdekatan dengan siswa yang cepat tanggap agar dapat saling membantu dalam belajar, memberikan pengarahan agar siswa memperbanyak latihan membaca AlQur'an dengan tajwid utamanya di rumah dan berupaya agar siswa masing-masing membawa media Al-Qur'an sehingga keterbatasan jumlah media dapat diatasi.

Sehubungan dengan kesimpulan penelitian di atas, maka diajukan saran sebagai berikut: Guru, agar lebih professional dalam mengajar serta mengoptimalkan potensi siswa sehingga penerapan ilmu tajwid dapat berhasil dengan baik dan terus berlangsung. Siswa, agar lebih memacu motivasi untuk belajar serta latihan yang banyak dalam membaca dan mengamalkan Al-Qur'an dimanapun berada.

\section{DAFTAR PUSTAKA}

Anwar, Hasan. 1985. Penyederhanaan Ilmu Tajwid. Surabaya: Bina Ilmu.

Budiningsih, A. (2005). Belajar Pembelajaran. Jakarta: PT Cipta dan Rineka.

Kurniasih, I \& Sari. (2014). Implementasi kurikulum konsep \& penerapan. Surabaya: Kata Pena.

Moleong, L. J. 2002. Metodologi Penelitian Kualitatif. Bandung: Remaja Karya

Munir, Ahmad \& Sudarsono. 1994. Ilmu Tajwid dan Seni Baca Al-Qur'an. Jakarta: Rineka Cipta.

Nata, Abuddin. 2000. Al-Quran dan Hadits. Jakarta Raja Grafindo Persada

Peraturan Daerah Kabupaten Bulukumba Nomor 06 Tahun 2003 tentang Baca Tulis Al-Quran.

Soenarto, Ahmad. 1988. Pelajaran Tajwid Praktis dan Lengkap. Jakarta: Bintang Terang

Suryosubroto. (2009). Proses Belajar Mengajar di Sekolah. Jakarta: Rineka Cipta. 
Undang-Undang Republik Indonesia, Nomor 20 Tahun 2003 tentang Sistem Pendidikan Nasional Beserta Penjelasannya. Bandung: Citra Umbara

Wadud, Abdul. 1995. Qur' an Hadits untuk Madrasah Tsanawiyah Kelas I. Semarang: Toha Putra

Wikipedia.com. 2020. Pembelajaran. (Online). Vol. 1. (http://www.wikipedia.com . diakses 24 Oktober 2020) 